\title{
Response to mydriatics in the African
}

\author{
V.P. EMIRU \\ Department of Ophthalmology, Makarere University Medical School, Kampala, Uganda
}

It is common clinical experience that the pupil in the African dilates slowly in response to mydriatics. Full mydriasis can be obtained in about 40 minutes in the Asian or European, but takes much longer in the African. This difference in response has been observed in the same clinic at the same time and using the same drug. Scott (1945) noted the need for stronger mydriatics to dilate the pupil in Negroes. There must be an intrinsic peculiarity in the African iris, and it has been shown that this is not due to faulty innervation (Scott, 1945).

An obvious peculiarity of the African iris is the abundant pigmentation. The present study has revealed that the relatively slower response of the pupil to mydriatics in the African is indeed related to pigmentation, and that the pupil in the albino African behaves differently. The exact mechanism by which pigmentation influences mydriasis is not clear, and anatomical and physiological studies have been carried out in an attempt to find a possible explanation.

\section{Methods}

(a) The rate of dilation of the pupil was compared in Africans, Europeans, and albino Africans, using homatropine 4 per cent. and phenylephrine 4 per cent. The subjects were studied in the same room in the same natural daylight. Phenylephrine was instilled into the right conjunctival sac and homatropine into the left conjunctival sac in all cases. An equal number of drops was instilled from the same bottle and the diameter of the pupil was measured at Io-min. intervals using a ruler.

(b) Comparative biomicroscopical studies were made on the African, European, and albino African irides.

(c) A comparative histological study was made on the African and European irides.

\section{Results}

\section{(a) Dilation of the pupil}

Full mydriasis was obtained after about 40 minutes in the Europeans, but in the darkskinned Africans dilation to the same extent could not be obtained even after 6o minutes. In the albino Africans dilation of the pupil was most brisk. There was no difference between the sexes, but dilation was a little slower in the older age group. Dilation started within 5 minutes in the Europeans and albino Africans, but in the dark Africans it started after about Io minutes. Mydriasis started earlier with homatropine, but the degree of dilation was about the same with both drugs after 30 to 40 minutes. In the dark Africans the effectiveness of both drugs was reduced in the same proportion in that the final degree of dilation was the same. The results are shown in the Table (opposite) and in Fig. I (overleaf). 
Table Dilation of pupil at I0-min. intervals. Diameter of the pupil (lower figures in each column are those of the left pupil)

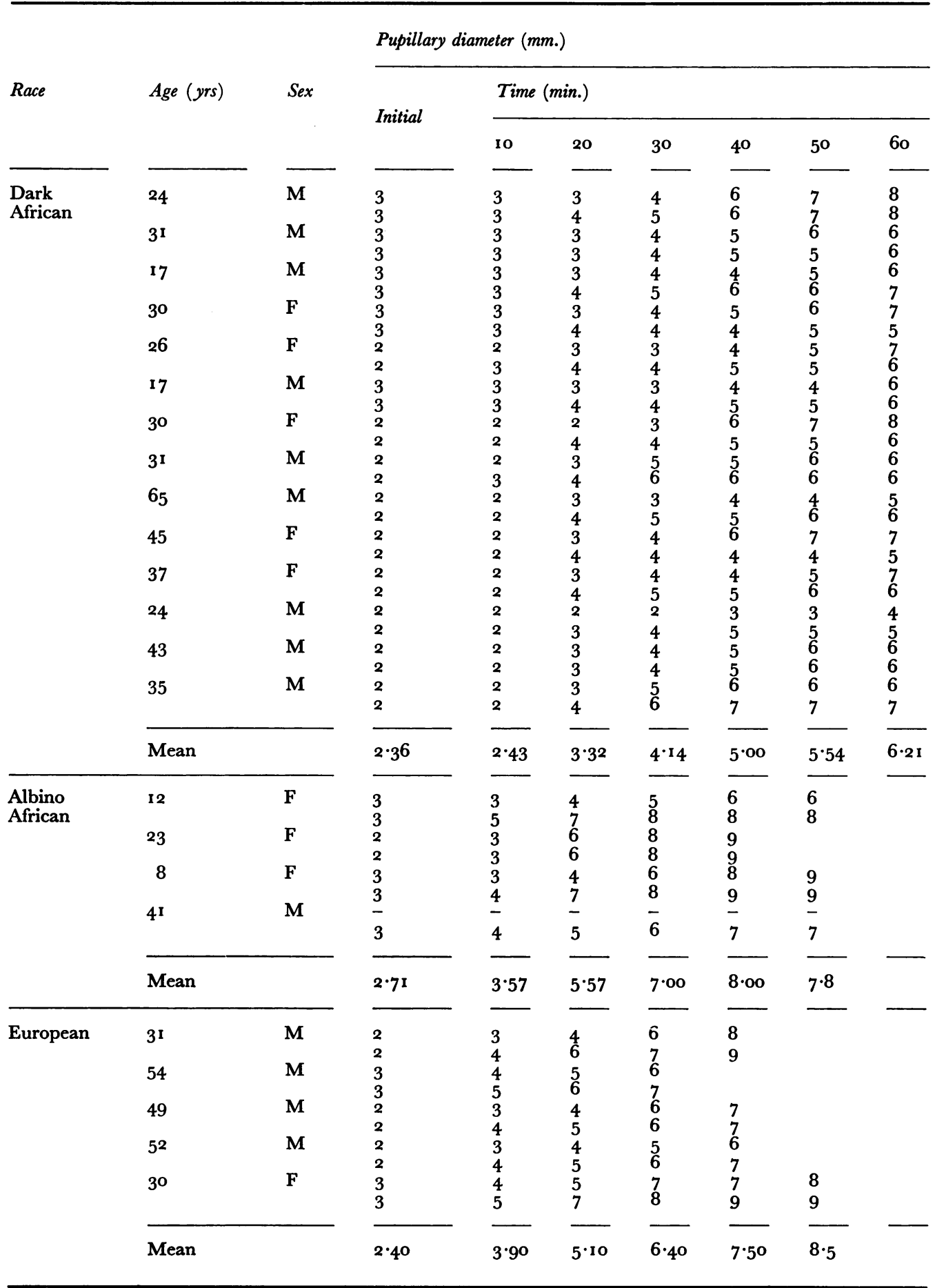




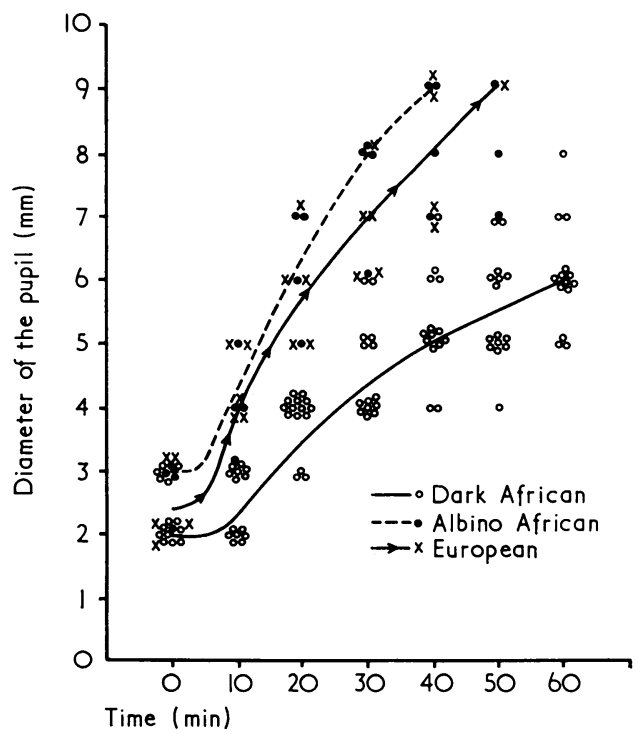

F I G. I Rate of dilation of the pupil by 4 per cent. homatropine in European, African, and albino African

\section{(b) Biomicroscopic appearance of the irides}

There are striking differences in the appearance of African and European irides. The $\overrightarrow{0}$ anterior surface of the African iris appears as a dense, opaque, brown "moss carpet", and is characterized by a paucity of surface markings. Its radial trabecular pattern is often 0 not seen except near the pupillary border, and the collarette, which divides the iris into the ciliary and pupillary portions, is sometimes not apparent. The crypts are few and $\overline{0}$ small and look like small pits near the pupillary border, while the peripheral pits of Fuchs appear as pinpoints.

In contrast, the European iris has a wealth of surface detail. Its anterior surface looks $\overrightarrow{\overrightarrow{0}}$ more porous. The radial trabecular lines are well marked and the collarette can always be identified. Numerous large crypts are present.

In the albino African these surface markings are even more obvious, with an apparent lack of pigment.

\section{(c) Histological differences between European and African irides}

The histology of the iris in the two races is basically the same, but the anterior border layer in the African iris is much thicker and more pigmented. All the pigment cells 9 contain large quantities of pigment. The stroma of the African iris contains more abundant $\frac{7}{0}$ branching pigment cells. The sphincter pupillae and the dilator pupillae and the posterior pigment epithelium do not appear to differ in the two races.

It is unreliable to compare the thickness of the irides from histological section as this $\tilde{O}$ depends upon the size of the pupil and other factors, but the impression is that the African iris may be thicker (Figs 2 to 5 , opposite).

\section{Discussion}

The rate of dilation of the pupil is determined partly by the rate of absorption of the $\frac{T}{0}$ mydriatic. A large proportion of a drug instilled into the conjunctival sac is absorbed through the cornea into the aqueous humour. Systemic absorption probably has little $\frac{\Omega}{\mathbb{D}}$ 


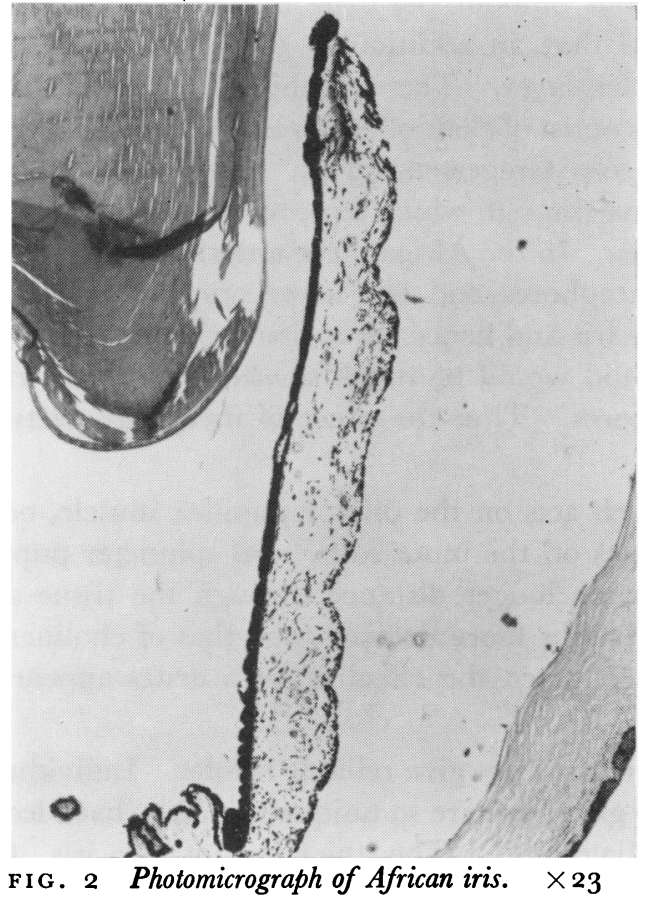

FIG. 2 Photomicrograph of African iris. $\times 23$

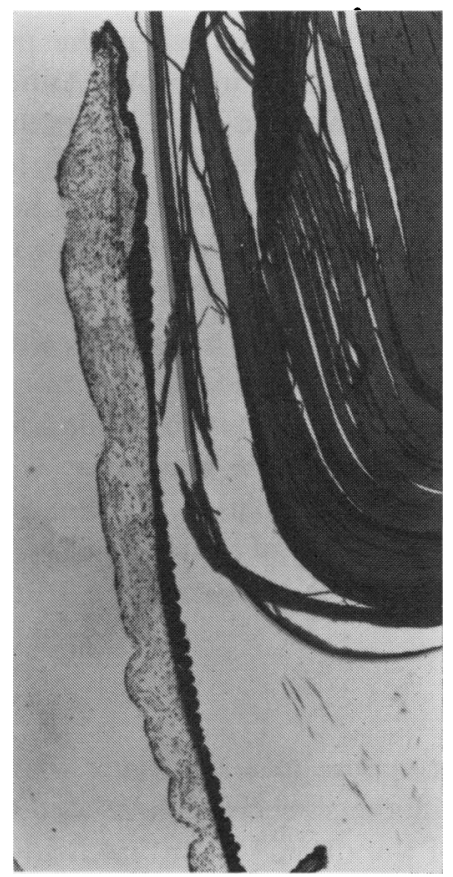

FIG. 4 Photomicrograph of European iris. $\times 23$

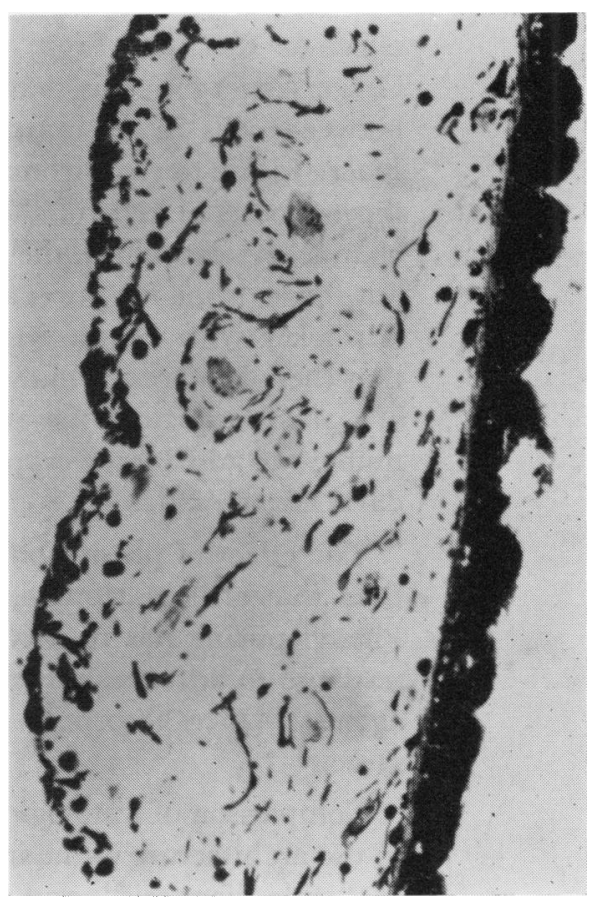

FIG. 3 Same African iris near the root. $\times$ I I 5

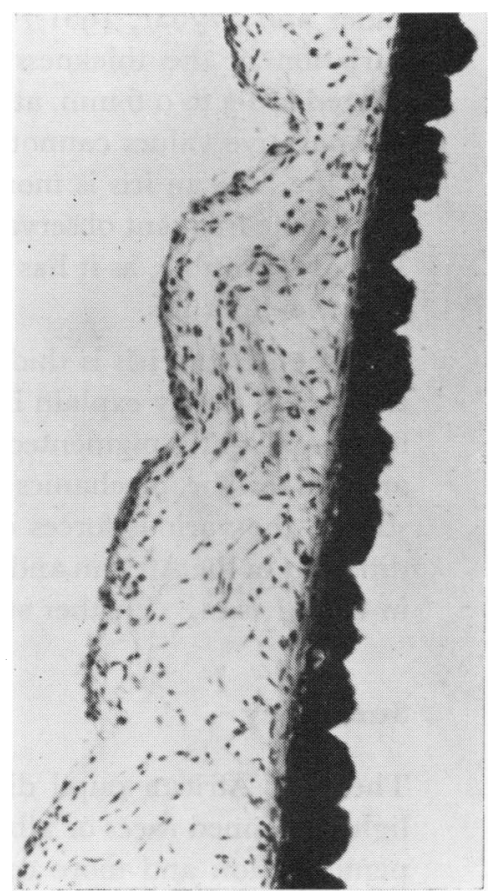

FIG. 5 Same European iris near the root. $\times$ II 5 
effect on the iris. From the aqueous humour the drug is absorbed by the iris surface. Gregersen (1960) has demonstrated that, in addition to the crypts, there are iris pores between cells in the anterior border layer. These openings communicate with tissue spaces within the iris stroma, which consist of clefts of Fuchs and tubular spaces surrounding the endothelial cells of the iris vessels (Gregersen, 1959). There is therefore a definite channel-system within the iris stroma through which aqueous humour passes freely in and out through the iris pores and crypts. In the African, the anterior border layer of the iris is thicker with denser iris chromatophores and has fewer crypts. It is also probable that there is more stroma within the iris and hence fewer tissue channels. The absorption of a mydriatic from the aqueous fluid would be much slower than in an iris with more numerous and larger crypts and pores. Thus the onset of mydriasis starts later in the dark African iris.

The effect of phenylephrine, which acts on the dilator pupillae muscle, occurred later 0 than that of homatropine, which acts on the more superficial sphincter pupillae muscle. of Phenylephrine has to traverse a much longer distance through the tissue spaces. The 0 response to adrenergic stimulators is thus more delayed than that of cholinergic blocking $\mathscr{E}_{\infty}$ agents. Once absorption had taken place the effect of both drugs appeared to be the $\cong$ same.

Comparison of histological features may not give reliable results. Individual variations in the architecture of the iris of any given eye are so unique that they have led to the cults of "irido-diagnosis" and "oculo-diagnosis". The thickness of the iris, for instance, varies according to the degree of dilation of the pupil. Immediately before death, the pupil dilates, but after death it gradually decreases in size to an average diameter of about $3.5 \mathrm{~mm}$. Fixatives diminish the size of the pupil still further to about 2 to $3 \mathrm{~mm}$. (DukeElder and Wybar, 196r). It has also been shown that there is considerable individual variation in the thickness of the iris. The average thickness when the pupil is semidilated is 0.3 to $0.6 \mathrm{~mm}$. at the collarette and $0.05 \mathrm{~mm}$. at the iris root. Although reliable comparative values cannot therefore be given, biomicroscopic study leaves the impression that the African iris is more compact, with possibly more stroma. This is further borne out by the frequent observation that iridodonesis is less common in aphakia in the African. It is also possible, as it has been noted before (McNair, I95I), that the dark iris is thicker than the light iris.

If the African iris is thicker and more compact, it would be less easily compressed, and this would partly explain its sluggish dilation, in that it may not be able to exert as much force as a lightly-pigmented iris is able to develop. Mapstone (1968) made a mathematical analysis of the mechanics of pupillary block in closed-angle glaucoma, which demonstrated the various forces exerted by the iris as the pupil dilated. These forces may be different in the African and could perhaps explain the rarity of acute closed-angle glaucoma in the African. Further study of this feature seems to be indicated.

\section{Summary}

The dark African pupil dilates more slowly in response to a mydriatic than that of the lighter-skinned races or albino Africans. This difference seems to be related to the deeper pigmentation and more compact architecture of the dark African iris, with fewer tissue channels. It is possible that the African iris may not be able to exert the force which may lead to pupillary block, such as lightly-pigmented iris is able to develop. 
I should like to acknowledge the useful suggestions which I have received from Prof. E. S. Perkins, Institute of Ophthalmology, London, and to thank Prof. N. Ashton, Department of Pathology, Institute of Ophthalmology, London, for supplying a specimen of European iris.

\section{References}

DUKE-ELDER, S., and WYBAR, K. c. (196I) “System of Ophthalmology", vol. 2, p. 169. Kimpton, London GREGERSEN, E. (1959) Acta ophthal. (Kbh.), 37, 199

( 1960$)$ "Studies on the Spongy Structure of the Human Iris and its Imbibition with the

Aqueous Humour". Munksgaard, Copenhagen

McNAIR, s. s. (195I) Amer. F. Ophthal., 34, 70

MAPSTONE, R. (1968) Brit. 7. Ophthal., 52, i9

SCOTT, J. G. (I945) Ibid., 29, I 2 